\title{
Demonstration of light chain monotypia in B cell non-Hodgkin's lymphomas using unfixed freeze-dried and formalin-fixed trypsinised paraffin sections
}

\author{
ZOLTÁN NEMES, VILMOS THOMÁZY, GYÖRGY SZEIFERT \\ From the Department of Pathology, University Medical School, H-4012 Debrecen, Hungary
}

SUMMARY Immunohistological light chain analysis was carried out in 55 patients with nonHodgkin's lymphoma of B cell origin. Unfixed freeze-dried paraffin sections were used to detect surface Ig and formaldehyde-fixed trypsinised sections to detect cytoplasmic Ig. Cytoplasmic Ig was seen inconstantly in freeze-dried paraffin sections. There was complete agreement with regard to the type of light chain between freeze-dried and formaldeyde-fixed trypsinised sections. Immunohistology showed the monotypic immunoglobulin light chains in $83 \%$ of cases when unfixed freeze-dried paraffin sections were used for sIg demonstration while only in $45 \%$ of cases when formaldehyde-fixed material was used for cIg detection. The efficiency of sIg demonstration in unfixed freeze-dried paraffin sections was comparable with that based on unfixed cryostat sections or on cell suspensions when the lymphocytic lymphoma/CLL group was excluded from the evaluation. The relatively low frequency of monotypic sIg positivity obtained in this group $(12 / 19)$ is due to the low density of surface Ig in CLL lymphocytes.

Since the majority of non-Hodgkin's lymphomas are of B cell lineage, a variety of techniques have been developed to document light chain monotypia in these neoplasms.

Cell suspension techniques often yield spurious results mostly due to non-representative aliquots of the neoplasm and contamination with residual non-neoplastic or reactive cells. Cell suspension studies have been reported to be unable to establish light chain monotypia in nearly half the cases of $B$ cell lymphomas in which immunohistological analysis was capable of establishing the monoclonal nature of the proliferation. ${ }^{1}$

A more useful method is to study sections of tissue. This allows assessment of the topographical relation between the neoplastic and non-neoplastic components. Immunohistological techniques after proteolytic digestion of routinely fixed paraffin section seem to be the most sensitive and reproducible methods for detecting cytoplasmic immunoglobulins (cIg) and other cytoplasmic antigens in tissue ${ }^{23}$ while surface immunoglobulins (sIg) are not detected by this method. ${ }^{4-6}$ Surface immunoglobulins have been reliably detected only on cryostat sections of fresh tissue,${ }^{7-10}$ on cryostat sections of tissue

Accepted for publication 10 February 1983 preserved in transport medium ${ }^{1112}$ or on unfixed freeze-dried paraffin sections. ${ }^{13}$ The latter method yields improved tissue morphology compared to cryostat sections.

In this report, we present the results of immunohistological light chain analysis in a series of patients with non-Hodgkin's lymphomas of B cell origin. We were interested in knowing: (i) the percentage of cases with monotypic sIg on unfixed freeze-dried paraffin sections; (ii) the percentage of patients with monotypic cIg on formaldehyde-fixed paraffin sections following standardised trypsinisation and (iii) the agreement between the two methods with regard to the type of light chains

\section{Material and methods}

Fresh lymph node biopsies, spleens and palatine tonsils have been studied from 55 patients with non-Hodgkin's lymphomas of B cell origin. The histological classification was performed according to the Kiel classification system. ${ }^{14}$ The biopsies have been split into two parts: one part used for freezedrying and the other fixed in $4 \%$ phosphatebuffered formaldehyde (prepared from paraformaldehyde). 
FORMALDEHYDE-FIXED TISSUES

Blocks of tissue (approx $5 \mathrm{~mm} \times 5 \mathrm{~mm} \times 3 \mathrm{~mm}$ ) were fixed in formaldehyde for $6 \mathrm{~h}$ at room temperature. The tissues were washed overnight in physiological saline and processed to paraffin as follows: $50 \%$ acetone (30 $\mathrm{min}), 100 \%$ acetone $(60 \mathrm{~min}$ $\times 3)$, xylene (15 min $\times 3$ ). Vacuum paraffin embedding was performed for $30 \mathrm{~min}$ at $55-56^{\circ} \mathrm{C}$. Paraffin sections $(5 \mu \mathrm{m})$ were cut, deparaffinised in xylene followed by acetone. These sections were used for staining methods (haematoxylin and eosin and Giemsa), and also for the immunohistological detection of cIg.

\section{UNFIXED FREEZE-DRIED TISSUES}

Blocks of tissue (approx $5 \mathrm{~mm} \times 5 \mathrm{~mm} \times 3 \mathrm{~mm}$ ) were snap frozen in dry ice isopentane mixture and freeze-dried for $36 \mathrm{~h}$ in an Edwards-Pearse EP D2 tissue dryer $\left(-45^{\circ} \mathrm{C}, 10^{-2}\right.$ Torr, in the presence of $\mathrm{P}_{2} \mathrm{O}_{5}$ ). The freeze-dried tissue was slowly warmed to $20^{\circ} \mathrm{C}$ and brought to atmospheric pressure prior to embedding. Vacuum paraffin embedding was performed for $30 \mathrm{~min}$ at $55-56^{\circ} \mathrm{C}$. Paraffin sections (5 $\mu \mathrm{m})$ were cut, deparaffinised in xylene followed by acetone and washed in Tris-saline for $5 \mathrm{~min}$ prior to immunohistology.

\section{TRYPSINISATION}

Formaldehyde-fixed sections were incubated at $37^{\circ} \mathrm{C}$ for $15 \mathrm{~min}$ in Tris- $\mathrm{HCl}$ buffer ( $\mathrm{pH} \mathrm{7.8)} \mathrm{con-}$ taining $0 \cdot 1 \%$ trypsin (Difco $1 / 250$ ) and $0.1 \% \mathrm{CaCl}_{2}$.

\section{INDIRECT IMMUNOFLUORESCENCE (IF) \\ TECHNIQUE}

Sections were washed in $0.05 \mathrm{M}$ Tris- $\mathrm{HCl}$ buffer (pH 7.4) and incubated for $30 \mathrm{~min}$ at room temperature with specific antisera diluted in Tris- $\mathrm{HCl}$ buffer containing $1 \%$ bovine serum albumin. Rabbit antihuman antisera were used in dilutions $1 / 100$ (freeze-dried material) and 1/400 (formaldehydefixed material). After $20 \mathrm{~min}$ washing in Tris- $\mathrm{HCl}$ buffer, the sections were incubated for $45 \mathrm{~min}$ with FITC-labelled polyvalent swine antirabbit Ig diluted $1 / 50$ in Tris $\mathrm{HCl}$ buffer. The sections were mounted in glycerol-Tris-saline. Immunofluorescence was viewed in a Leitz Orthoplan microscope equipped with Ploemopak epi-illuminator and narrow band filter system. Control sections were regularly examined with normal rabbit serum instead of specific antisera.

\section{PEROXIDASE-ANTIPEROXIDASE (PAP) TECHNIQUE}

For inhibition of endogenous peroxidase activity sections were treated for $30 \mathrm{~min}$ with a mixture of methanol and $\mathrm{H}_{2} \mathrm{O}_{2}$ at $22^{\circ} \mathrm{C}(99 \mathrm{ml}$ methanol $+1 \mathrm{ml}$
$30 \% \mathrm{H}_{2} \mathrm{O}_{2}$ ). The sections were rinsed in Tris- $\mathrm{HCl}$ buffer and subsequently incubated for $30 \mathrm{~min}$ at room temperature with specific antisera diluted in Tris- $\mathrm{HCl}$ buffer containing $1 \%$ bovine serum albumin. Rabbit antihuman antisera were used in dilutions 1/100 (freeze-dried material) and 1/400 (formaldehyde-fixed material). After $20 \mathrm{~min}$ washing in Tris- $\mathrm{HCl}$ buffer the sections were incubated in a 1/40 diluted polyvalent swine antirabbit $\mathrm{Ig}$ for 45 $\mathrm{min}$. This step was succeeded by $20 \mathrm{~min}$ washing in Tris- $\mathrm{HCl}$ buffer and an incubation in peroxidaseantiperoxidase complex diluted $1 / 100$ in Tris- $\mathrm{HCl}$ buffer for $45 \mathrm{~min}$. Sections were subsequently washed in Tris- $\mathrm{HCl}$ buffer. The peroxidase activity was demonstrated with 3,3'-diaminobenzidine reaction. ${ }^{15}$ Control sections were routinely examined with normal rabbit serum instead of specific antisera.

\section{ANTISERA AND REAGENTS}

Rabbit antisera specific to human kappa and lambda light chains, polyvalent swine antirabbit Ig, polyvalent swine antirabbit Ig FITC-labelled, normal rabbit serum and rabbit PAP complex were obtained from DAKO-immunoglobulins Ltd (Copenhagen, Denmark). 3,3'-diaminobenzidine free base was purchased from Sigma Chemical Co. (St Louis, Mo, USA).

\section{INTERPRETATION OF IMMUNOHISTOLOGICAL}

RESULTS

A case was regarded as sIg-positive when the majority of cells showed sIg positivity. For a case to be classified as cIg positive, a minimum number of $5 \%$ positive cells was required.

\section{Results}

The distribution of cases between the different histological groups of the Kiel classification system and the results of light chain analysis obtained by IF on unfixed freeze-dried sections and those obtained by IF or PAP technique on formaldehyde-fixed trypsinised sections, is shown in Table 1.

In all surgical biopsies and necropsy cases giving a monotypic light chain reaction there was complete agreement with regard to the type of light chain between freeze-dried and formaldehyde-fixed trypsinised sections.

The immunohistological demonstration of sIg was successful in freeze-dried sections but that of cIg was unreliable. Distinction between SIg and cIg positivity was difficult when the cytoplasmic rim of the cell was narrow. Furthermore, it was often felt that the pe $r$ ztration of antisera into the cytoplasm of unfixed freeze-dried cells was restricted to the periphery of 
Table 1 Monotypic $(M)$ and polytypic $(P)$ light chain reactivity of sIg (unfixed freeze-dried paraffin sections) and clg (formaldehyde-fixed trypsinised sections) in relation to histological groups

\begin{tabular}{|c|c|c|c|c|}
\hline Diagnosis & $s I g$ & $c l g$ & No of cases & No of necropsy cases \\
\hline ML lymphocytic/CLL & $\begin{array}{l}\mathbf{M} \\
\mathbf{M} \\
\mathbf{M} \\
\mathbf{P} \\
\text { - }^{*}\end{array}$ & $\begin{array}{l}\mathbf{M} \\
\mathbf{P} \\
\mathbf{P} \\
\mathbf{P} \\
-\end{array}$ & $\begin{array}{l}4 / 19 \\
6 / 19 \\
2 / 19 \\
2 / 19 \\
2 / 19 \\
3 / 19\end{array}$ & 1 \\
\hline ML immunocytic, lymphoplasmacytoid & $\underline{\mathbf{M}}$ & $\begin{array}{l}\mathbf{M} \\
\mathbf{M}\end{array}$ & $\begin{array}{l}6 / 7 \\
1 / 7\end{array}$ & $\begin{array}{l}2 \\
1\end{array}$ \\
\hline $\begin{array}{l}\text { ML immunocytic, lymphoplasmacytic } \\
\text { ML immunocytic, polymorphic }\end{array}$ & $\begin{array}{l}\mathbf{M} \\
\mathbf{M} \\
\mathbf{M} \\
-\end{array}$ & $\begin{array}{l}\mathbf{M} \\
\mathbf{M} \\
\mathbf{P} \\
\mathbf{P}\end{array}$ & $\begin{array}{l}1 / 1 \\
2 / 4 \\
1 / 4 \\
1 / 4\end{array}$ & $\begin{array}{l}1 \\
1 \\
1\end{array}$ \\
\hline ML centrocytic & $\mathbf{M}$ & - & $3 / 3$ & \\
\hline ML centroblastic-centrocytic & $\begin{array}{l}\mathbf{M} \\
\mathbf{M}\end{array}$ & $\underline{\mathbf{M}}$ & $\begin{array}{l}4 / 7 \\
3 / 7\end{array}$ & 1 \\
\hline ML centroblastic & $\begin{array}{l}\mathbf{M} \\
\mathbf{M}\end{array}$ & $\underline{\mathbf{M}}$ & $\begin{array}{l}3 / 4 \\
1 / 4\end{array}$ & \\
\hline ML immunoblastic & $\begin{array}{l}\mathbf{M} \\
\mathbf{M}\end{array}$ & $\underline{\mathbf{M}}$ & $\begin{array}{l}4 / 5 \\
1 / 5\end{array}$ & 1 \\
\hline $\begin{array}{l}\text { Burkitt's lymphoma } \\
\text { Hairy cell leukaemia }\end{array}$ & $\mathbf{M}$ & $\underline{-}$ & $\begin{array}{l}3 / 3 \\
2 / 2\end{array}$ & \\
\hline
\end{tabular}

"In the peripheral blood, lymphocytes were sIg-positive by direct immunofluorescence utilising $F\left(a^{1}\right)_{2}$ fragments of rabbit antihuman immunoglobulin antiserum.

the cytoplasm, giving a marginal staining pattern instead of diffuse cytoplasmic staining (Fig. 9a). Thus, the sIg reactivity indicated in Table 1 may overlap cIg staining. In formaldehyde-fixed trypsinised sections, however, IF or PAP techniques demonstrated only cIg reactivity.

Immunohistological results of light chain analysis in various histological groups were as follows:

\section{Malignant lymphoma lymphocytic/CLL}

As shown in Table 1, 12 of 19 patients gave monotypic staining for sIg in unfixed freeze-dried sections (Figs. 1a and b). Kappa chain was detected in nine cases and lambda chain in three cases. In addition to monotypic sIg reactivity, seven cases revealed moderate cIg staining of the same light chain type in plasmacytoid lymphocytes. Such cells occurred focally and usually did not exceed $2 \%$ of the population. Polytypic sIg was observed in two cases. Polytypic cIg, usually in intensely stained mature plasma cells, was seen in four cases. In formaldehyde-fixed trypsinised sections, monotypic cIg (exceeding $5 \%$ of the population) was demonstrated in four patients, polytypic cIg in six patients with IF or PAP methods (Fig. 2).

\section{Malignant lymphoma immunocytic, \\ lymphoplasmacytoid}

All cases had monotypic cIg positivity in formaldehyde-fixed trypsinised sections with IF or PAP methods (Figs. 3a and b). Kappa chain was detected in five cases, lambda chain in two cases.
The earliest site of Ig accumulation is in the perinuclear space. Further accumulation at this site may indent the nucleus giving rise to intranuclear inclusions (Dutcher bodies)(Figs. $4 a$ and $b$ ). If the endoplasmic reticulum is the site of Ig accumulation, the staining pattern is often granular. This is seen in most extreme form as intracytoplasmic inclusions (Russell bodies). Six of seven cases showed monotypic sIg as well as cIg in unfixed freeze-dried material.

\section{Malignant lymphoma immunocytic, lymphoplasmacytic}

There was monotypic sIg staining (lambda) in lymphocytes and a moderate cIg staining in plasma cells in unfixed freeze-dried material (Fig. 5). The plasma cells showed lambda chain positivity in formaldehyde-fixed trypsinised sections.

\section{Malignant lymphoma immunocytic, polymorphic}

Three out of four patients showed monotypic sIg positivity in unfixed freeze-dried sections. Kappa chain was demonstrated in two, lambda chain in one case. Monotypic cIg positivity was detected in one biopsy material (lambda) and polytypic cIg positivity in a necropsy case. In formaldehyde-fixed trypsinised sections cIg positivity was evident in all cases but monotypic light chain composition was found only in two cases (Figs. 6a and b)

\section{Malignant lymphoma centrocytic}

This group consists of biopsies from three patients. They all contained monotypic sIg in unfixed freeze- 

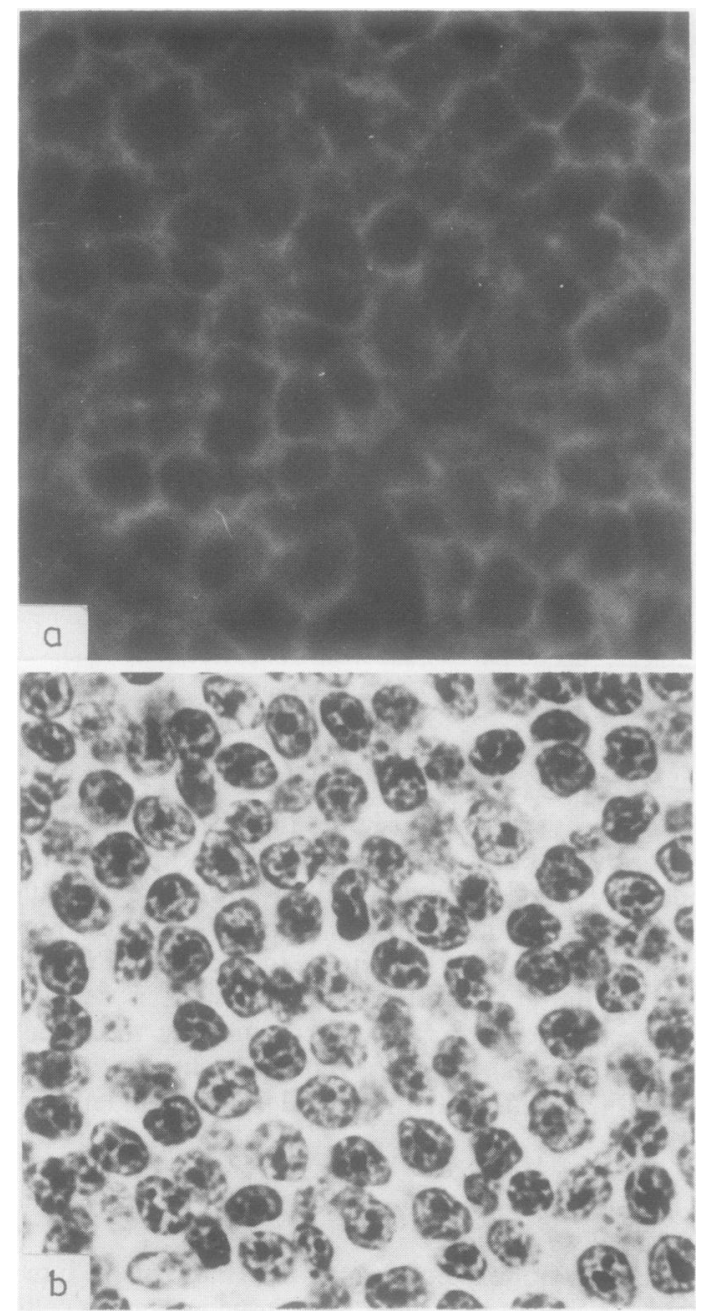

Fig. 1 (a) Malignant lymphoma lymphocytic/CLL. Kappa chain detection by IF on freeze-dried paraffin section. Weak positivity on the surface of cells. $\times 800(b)$

Formaldehyde-fixed section stained by haematoxylin and eosin. Small lymphocytes have regular round nuclei with coarse granular chromatin. $\times 800$

dried sections (kappa). No cIg positivity was observed either in unfixed freeze-dried or formaldehyde-fixed trypsinised sections (Figs. 7a, b and c).

\section{Malignant lymphoma centroblastic-centrocytic}

All of the seven cases showed monotypic sIg positivity whereas true cIg positivity was not observed in unfixed freeze-dried paraffin sections. Kappa chain was found in four, lambda chain in three cases. In the nodular type, the monotypic sIg pattern was

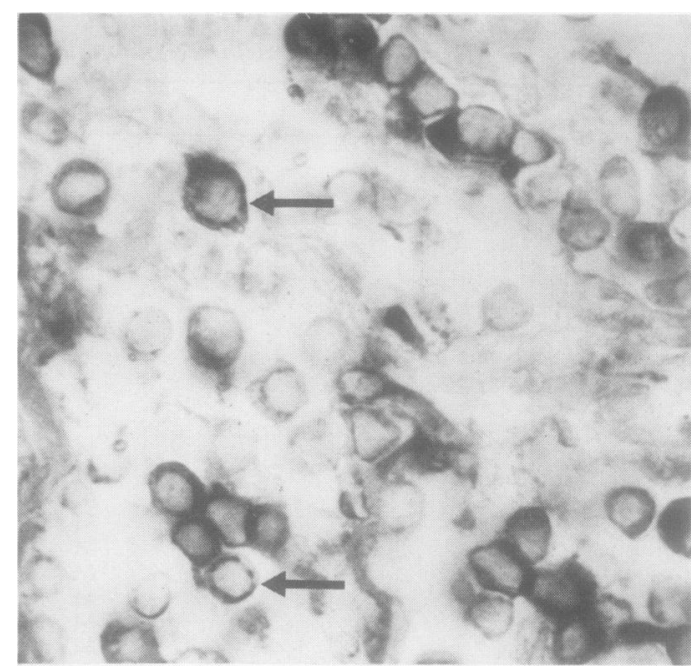

Fig. 2 Malignant lymphoma lymphocytic/CLL. Kappa chain detection by PAP on formaldehyde-fixed trypsinised section. A number of cytoplasmic lymphocytes show cIg positivity. The earliest site of Ig accumulation is the perinuclear space (arrows) $\times 800$

restricted to the nodules (Figs. $8 \mathrm{a}$ and $\mathrm{b}$ ). In formaldehyde-fixed trypsinised sections monotypic cIg positivity was established in four cases.

\section{Malignant lymphoma centroblastic}

All of the four cases showed monotypic sIg positivity (Figs. 9a and b). Kappa chain was found in two cases and lambda chain in two cases. Unequivocal cIg positivity was observed only in scattered plasma cells in two cases in freeze-dried material. In formaldehyde-fixed trypsinised sections, three of the four cases gave monotypic clg positivity in more than $5 \%$ of the cell population. The majority of these cells were large blast cells, plasma cells were inconspicuous.

\section{Malignant lymphoma immunoblastic}

In unfixed freeze-dried sections, all of the five cases showed monotypic sIg positivity in immunoblasts. Kappa chain was detected in four, lambda chain in one case. True cIg positivity was not observed in these cells. In formaldehyde-fixed trypsinised sections, however, the majority of immunoblasts gave monotypic cIg positivity in four of the five cases studied (Figs. 10a and b).

\section{Malignant lymphoma Burkitt type}

All of the three cases revealed monotypic sIg staining in unfixed freeze-dried sections. Kappa chain was detected in one, lambda chain in two cases. No cIg positivity was observed either in unfixed freezedried or formaldehyde-fixed trypsinised sections. 

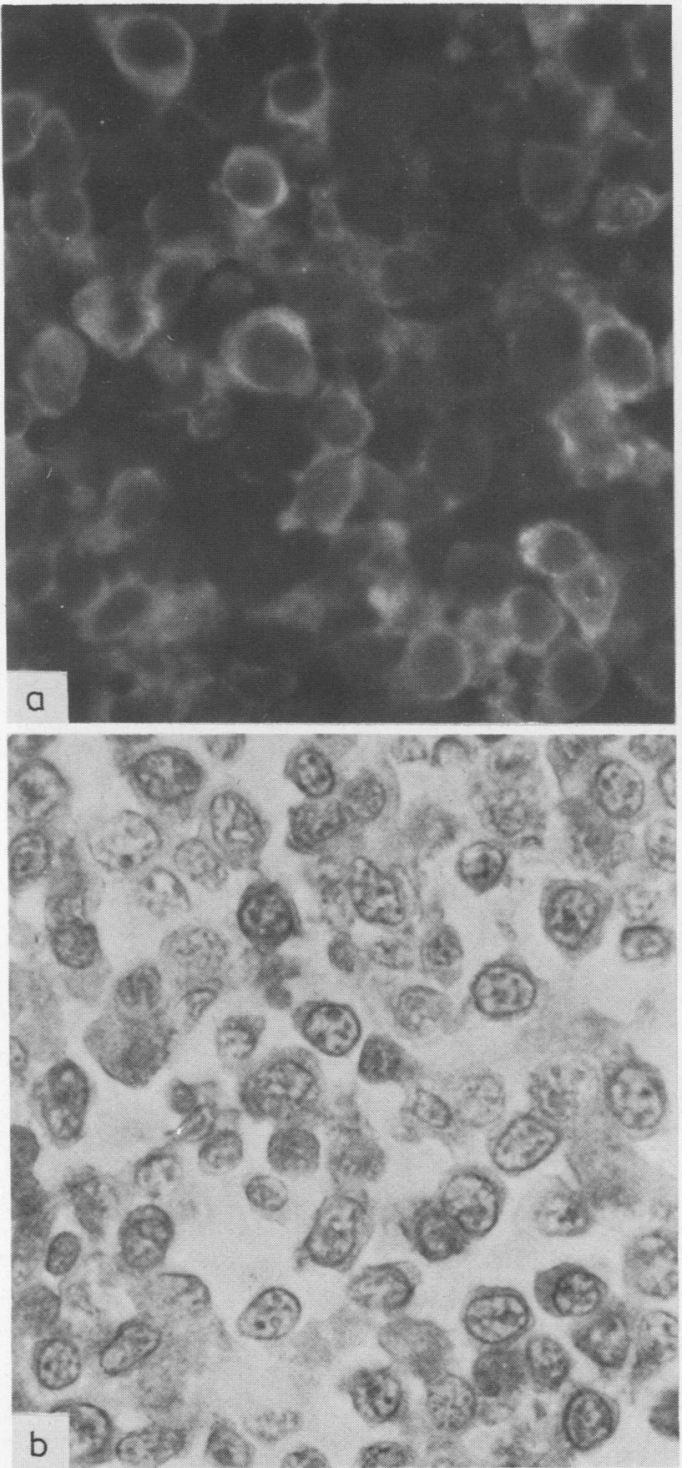

Fig. 3 (a) Malignant lymphoma immunocytic, lymphoplasmacytoid. Lambda chain detection by IF on formaldehyde-fixed trypsinised section. Plasmacytoid lymphocytes show various amounts of clg. Higher amounts of clg appear granular. $\times 800$ (b) Identical section slightly post-stained by haematoxylin and eosin. Monotonous picture of plasmacytoid lymphocytes. $\times 800$



Fig. 4 (a) Malignant lymphoma immunocytic, lymphoplasmacytoid. Kappa chain detection by IF on formaldehyde-fixed trypsinised section. Plasmacytoid cells contain moderate amounts of clg and occasional intensely fuorescent intranuclear inclusions (arrows). $\times 800$ (b) Adjacent section stained by haematoxylin and eosin. The plasmacytoid lymphocytes have ample cytoplasm, eccentric nuclei with a cartwheel chromatin pattern. Some of the cells show nuclear inclusions (Dutcher bodies) indicated by arrows. $\times 800$ 


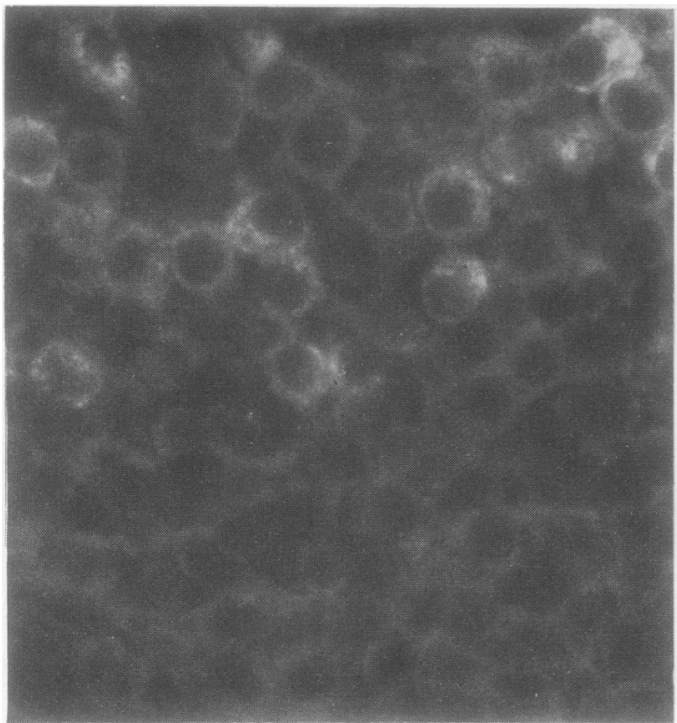

Fig. 5 Malignant lymphoma immunocytic,

lymphoplasmacytic. Lambda chain detection by IF on freeze-dried paraffin section. Lymphocytes show weak marginal ftuorescence, plasma cells show intense granular cIg positivity. $\times 800$

\section{Hairy cell leukaemia}

All of the two cases showed monotypic sIg staining (kappa) in unfixed freeze-dried sections (Figs. 11a and b). Cytoplasmic Ig positivity could not be detected in formaldehyde-fixed trypsinised sections.

The efficiency of immunohistological demonstration of light chain monotypia in unfixed freeze-dried paraffin sections (sIg) and in formaldehyde-fixed trypsinised sections (cIg) is summarised in Table 2 .

\section{Discussion}

Monotypic surface and/or cytoplasmic immunoglobulins in lymphoid cells have been considered the criterion by which the B cell nature of neoplastic lymphoid cell populations is established. Immunohistological methods on fixed paraffin embedded tissues, although preferable in terms of convenience and morphology, are limited to the detection of cytoplasmic constituents, including cIg, ${ }^{4-6}$ while surface immunoglobulins are reliably detected in unfixed tissue..$^{7-1013}$

Table 2 Occurrence of light chain monotypia in non-Hodgkin's lymphomas of B cell lineage

\begin{tabular}{lll}
\hline sIg positive & $46 / 55$ & $(83 \%)$ \\
cIg positive & $25 / 55$ & $(45 \%)$ \\
Total positive & $47 / 55$ & $(85 \%)$ \\
(sIg and/or cIg) & & \\
\hline
\end{tabular}
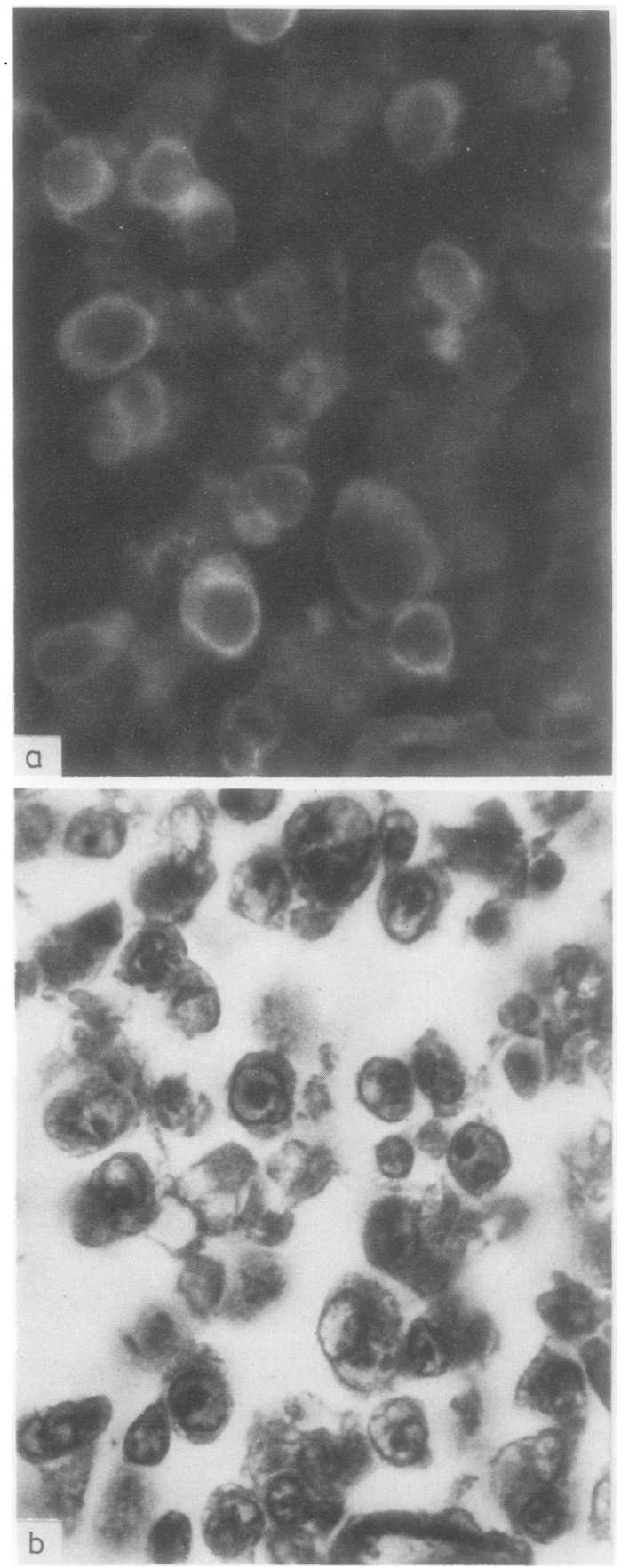

Fig. 6 (a) Malignant lymphoma immunocytic, polymorphic. Kappa chain detection by IF on formaldehyde-foxed trypsinised section. Immunocytes have stronger, large blasts weak clg positivity. $\times 800$ (b) Identical section slightly post-stained by haematoxylin and eosin. Immunocytes, centrocytes and large blasts with irregular nuclei (centroblasts). $\times 800$ 

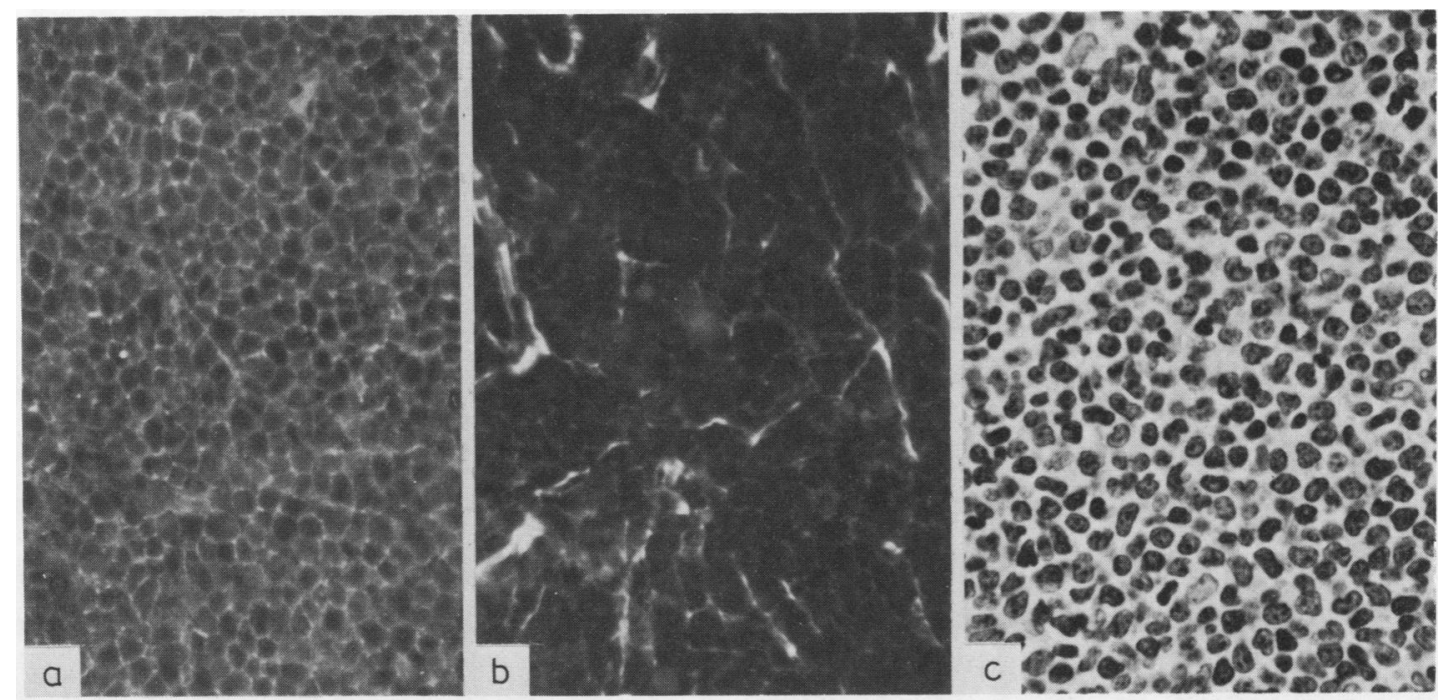

Fig. 7 (a) Malignant lymphoma centrocytic. Kappa chain detection by IF on freeze-dried paraffin section. Strong sIg positivity on all cells. $\times 200$ (b) Adjacent section stained by IF for lambda chains. Only the connective tissue framework is stained. $\times 200$ (c) Formaldehyde-fixed section stained by haematoxylin and eosin. Monotonous field of centrocytes with nuclear irregularities and dense granular chromatin structure. $\times 200$



Fig. 8 (a) Malignant lymphoma centroblastic-centrocytic, nodular. Kappa chain detection by IF on freeze-dried paraffin section. Intense sIg positivity restricted to the nodule. $\times 130$ (b) Formaldehyde-fixed section stained with Gomori's reticulin technique. The nodular architecture is clearly indicated. $\times 50$ 

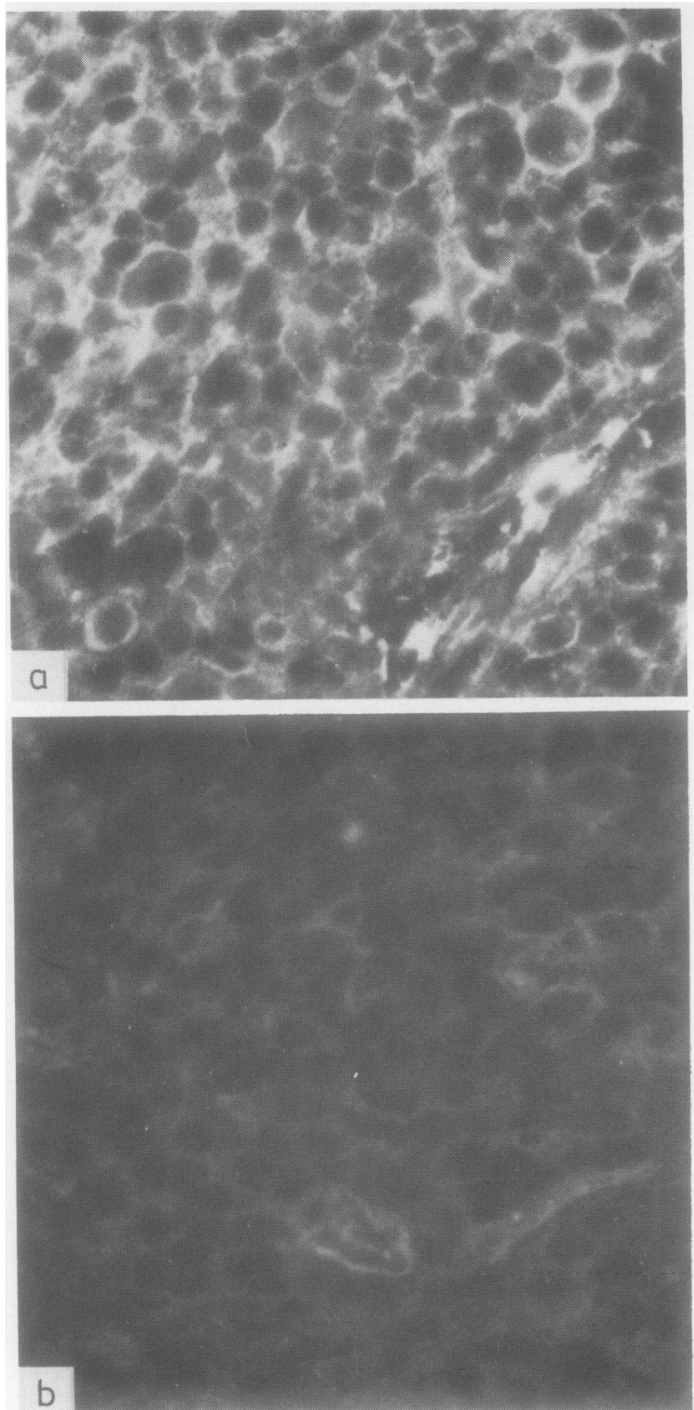

Fig. 9 (a) Malignant lymphoma centroblastic. Lambda chain detection by IF on freeze-dried paraffin section. Intense marginal staining of large and smaller cells. $\times 400$ (b) Adjacent section stained by IF for kappa chain. Slight background staining. Small vessels are moderately stained $\times 400$

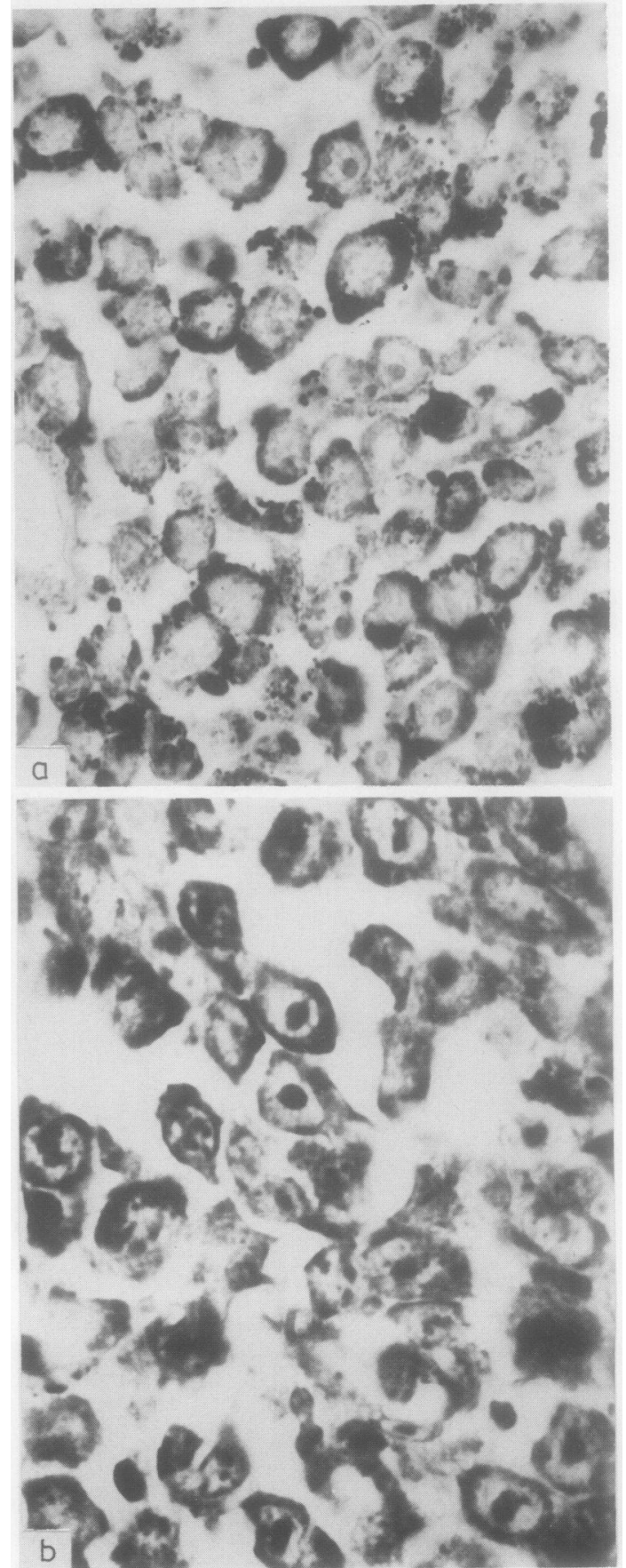

Fig. 10 (a) Malignant lymphoma immunoblastic. Kappa chain detection by PAP on formaldehyde-fixed trypsinised section. Various amounts of granular cIg in immunoblasts. $\times 800$ (b) Adjacent section stained by Giemsa.

Immunoblasts have strongly basophilic cytoplasm, vesicular nuclei with prominent central nucleoli. $\times 800$ 


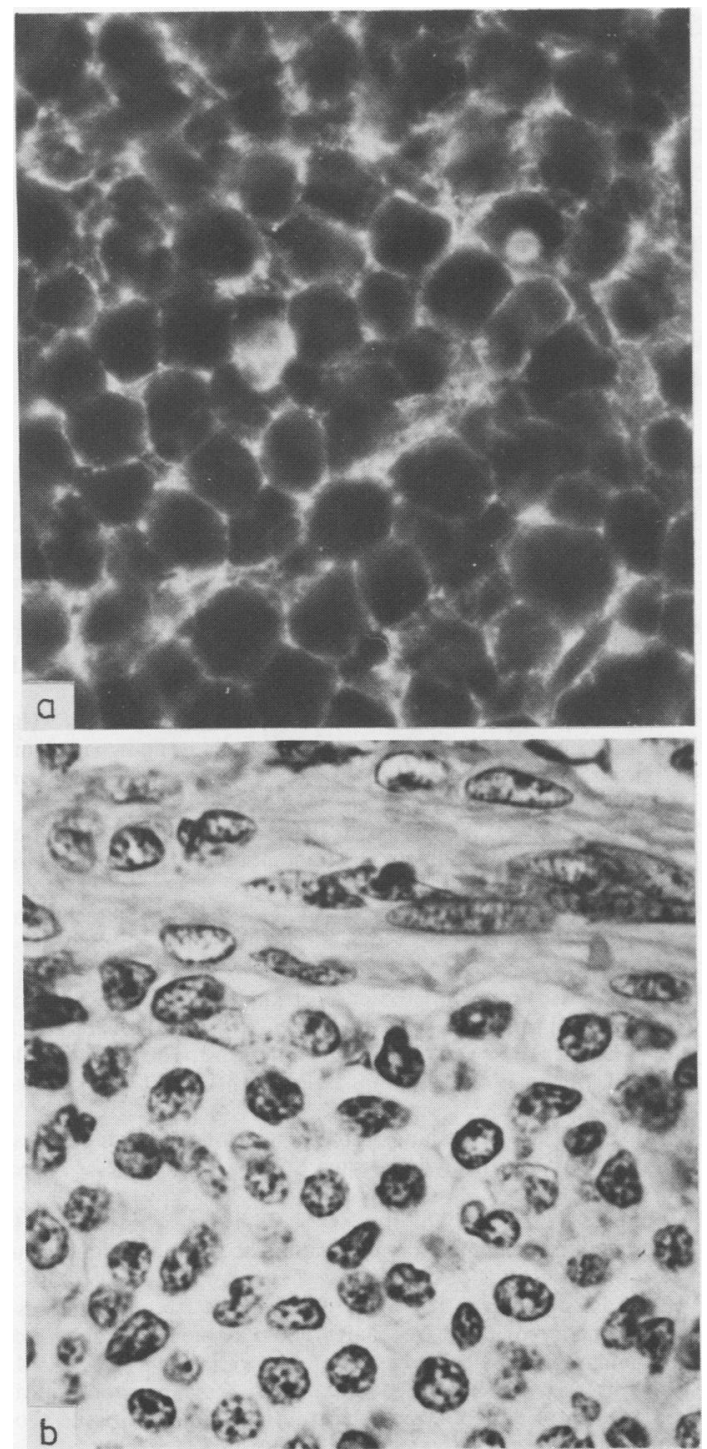

Fig. 11 (a) Hairy cell leukaemic infiltration in the spleen. Kappa chain detection by IF on freeze-dried paraffin section. Intense sIg positivity on all cells. $\times 800$ (b) Formaldehyde-fixed paraffin section stained by haematoxylin and eosin. Uniform small cells with granular nuclear chromatin and indistinct cytoplasm surround a splenic arteriole (top) $\times 800$
Most of the immunohistological studies on the relative frequency of $\mathrm{cIg}$ positive cases in B cell non-Hodgkin's lymphomas rely on undigested paraffin sections. ${ }^{516-19}$ The immunohistological staining of formalin-fixed tissue without proteolytic digestion is insensitive and capricious. ${ }^{320}$ Comparative immunohistological studies employing efficient methods for detecting the monotypic light chain composition of sIg and cIg in B cell non-Hodgkin's lymphomas are lacking. The present study is based on unfixed freeze-dried paraffin sections to detect $\operatorname{sIg}^{13}$ and on formaldehyde-fixed trypsinised sections to detect cIg. $^{2}$

Out of 55 B cell lymphomas $46(83 \%)$ revealed monotypic sIg positivity by IF in unfixed freezedried sections. IF has been found slightly superior to PAP to detect sIg on cryostat sections ${ }^{21}$ or on unfixed freeze-dried paraffin sections. ${ }^{13}$ The efficiency of the method can only be determined in comparison with studies based on a collection of cases with a similar distribution of histological types. Using cell suspensions, 56/66 (85\%) revealed monotypic sIg staining in a collection of B cell non-Hodgkin's lymphomas similar to ours with regard to the distribution of histological types. ${ }^{22}$ Another study, based on the direct immunoperoxidase technique and unfixed cryostat sections yielded $29 / 30(96 \%)$ cases with monotypic staining pattern. ${ }^{10}$ The ratio of lymphocytic lymphoma/CLL group to other histological types cannot be determined from this publication. If such cases are excluded from our material 34/36 (94\%) shows monotypic sIg positivity which is superior to the efficiency of direct immunofluorescence and cell suspension employed on a similarly corrected material $^{22}$ : $50 / 60(83 \%)$.

The relatively low proportion of cases with monotypic sIg positivity in the lymphocytic lymphoma/ CLL group (12/19) is due to the constant low density of sIg in CLL (tenfold decrease when compared to normal lymphocytes ${ }^{23}$ ). This group has well defined cytomorphological features and it is easily distinguished from immunocytomas by histological staining methods. Immunohistology, however, reveals scattered plasmacytoid lymphocytes in 7 of 12 sIg positive cases showing cIg of the same light chain type as the sIg on the majority of lymphocytes in unfixed freeze-dried sections. The proportion of such cells exceeded $5 \%$ of the population in formaldehyde-fixed trypsinised sections only in four cases. Such cases are classified as LP immunocytomas by the Lennert group. ${ }^{24} 20$

We did not reclassify these cases as immunocytomas on the basis of immunohistology. These four cases can be taken as borderline cases between lymphocytic lymphoma/CLL and lympho- 
plasmacytoid immunocytoma. The relatively high frequency of monotypic sIg positive cases with occasional cIg positive cells (7/12) is a characteristic feature of the lymphocytic lymphoma/CLL group. In most patients with CLL, the leukaemic B lymphocytes are "frozen" at a relatively early stage of maturation. In some of the patients, however, some leukaemic lymphocytes are able to escape the block and to mature into secreting plasma cells. ${ }^{25-27}$ It is hard to explain why cIg positive cells are so efficiently detected in unfixed freeze-dried material in this group while cIg in other histological types of non-Hodgkin's lymphoma tends to give sIg-like marginal staining in unfixed freeze-dried sections. Therefore the presence of cIg positive cells can only be reliably detected in formaldehyde-fixed trypsinised sections.

The constant monotypic cIg positivity in LP immunocytomas (lymphoplasmacytoid and lymphoplasmacytic) is in agreement with the findings of others using the same technique. ${ }^{322}$ Malignant lymphoma immunocytic, polymorphic cannot be compared with other studies since these cases are probably included in the follicle centre cell lymphomas ${ }^{28}$ or if they are composed predominantly of large cells they are termed as immunoblastic lymphomas.

Malignant lymphoma centrocytic is characterised by a strong monotypic sIg positivity and lack of cIg. The same pattern is found in Burkitt's lymphoma and in hairy cell leukaemia.

Malignant lymphoma centroblastic-centrocytic showed constant monotypic sIg positivity and cIg positivity in four out of seven patients. This ratio of cIg positive cases is less than $81 \%$ found in follicular centroblastic-centrocytic lymphomas by Stein et al ${ }^{20}$ or $68 \%$ found in follicle centre cell lymphomas by Isaacson $e t a^{3}$ but is higher than that found by Landaas et $a^{22}: 26 \%$ of follicular and $33 \%$ of diffuse centroblastic-centrocytic lymphomas.

Malignant lymphoma centroblastic revealed constant monotypic sIg positivity and three of four cases with cIg positivity. The latter ratio is similar to the $68 \%$ found in centroblastic lymphomas by Stein $e t$ $a l^{20}$ or to the $68 \%$ found in follicle centre cell lymphomas by Isaacson $e^{t} a^{3}$ but exceeds the $40 \%$ obtained in centroblasic lymphomas by Landaas $e t$ al. ${ }^{22}$

Malignant lymphoma immunoblastic yielded constant monotypic sIg positivity and cIg positivity in four of five cases. The latter ratio is among the best in the literature: $15 / 30$ found by Stein et al, ${ }^{20} 11 / 16$ found by Landaas $e t a l^{22}$ and $4 / 4$ found by Isaacson et al. ${ }^{3}$

It is noteworthy that immunohistology by itself provided confirmatory evidence for the diagnosis of $B$ cell lymphoma in $83 \%$ of cases when unfixed freeze-dried paraffin sections were used, while only in $45 \%$ of cases when an improved technique for cIg demonstration was used on formaldehyde-fixed material. The sIg demonstration in unfixed freezedried paraffin sections has special diagnostic advantage in the following diagnostic groups: malignant lymphoma centrocytic, Burkitt's lymphoma and hairy cell leukaemia.

We are grateful to Mrs Gabriella Nagy for her excellent technical assistance.

\section{References}

' Tubbs RR, Sheibani K, Weiss RA, Sebek BA, Deodhar SD. Tissue immunomicroscopic evaluation of monoclonality of $B$ cell lymphomas. Comparison with cell suspension studies. Am J Clin Pathol 1981;76:24-8.

${ }^{2}$ Mepham BL, Frater W, Mitchell BS. The use of proteolytic enzymes to improve immunoglobulin staining by the PAP technique. Histochem J 1979;11:345-57.

${ }^{3}$ Isaacson P, Wright DH, Judd MA, Jones DB, Payne SV. The nature of immunoglobulin-containing cells in malignant lymphoma: an immunoperoxidase study. J Histochem Cytochem 1980;28:761-70.

4 Garvin AJ, Spicer SS, McKeever PE. The cytochemical demonstration of intracellular immunoglobulin. Am J Pathol 1976;82:457-78.

5 Davey FR, Halliday D, Marucci AA, Gottlieb AJ. Detection of intracellular and cell surface immunoglobulin in nonHodgkin's lymphoma. Hum Pathol 1978;9:285-94.

- Taylor CR. Immunoperoxidase techniques. Practical and theoretical aspects. Arch Pathol Lab Med 1978;102:113-21.

' Levy R, Warnke R, Dorfman RF, Haimovich J. The monoclonality of human B cell lymphomas. J Exp Med 1977;145:1014 28.

${ }^{8}$ Warnke R, Levy R. Immunopathology of follicular lymphomas. A model of B lymphocyte homing. $N$ Engl $J$ Med 1978;298:481-6.

' Hoffmann-Fezer G, Thierfelder S, Pielsticker K, Rodt H. Immunohistochemical demonstration of cell surface antigens on tissue sections of lymphomas. Leuk Res 1979;3:297-304.

${ }^{10}$ Tubbs RR, Sheibani K, Weiss RA, Sebek BA. Immunohistochemistry of fresh-frozen lymphoid tissue with the direct immunoperoxidase technic. Am J Clin Pathol 1981;75:172-4.

" Borowitz MJ, Croker BP, Burchette J. Immunocytochemical detection of lymphocyte surface antigens in fixed tissue sections. J Histochem Cytochem 1982;30:171-4.

${ }^{12}$ Giorno R. Evaluation of a tissue transport medium for immunological characterization of benign and malignant lymphoid tissues. Am J Clin Pathol 1982;78:8-13.

${ }^{13}$ Nemes Z, Thomázy V, Szeifert G. Sensitivity and specificity of immunohistological methods on freeze-dried paraffin sections. J Immunol Methods 1982;49:53-64.

14 Lennert K. Malignant lymphomas other than Hodgkin's disease. Berlin, Heidelberg and New York: Springer-Verlag, 1978.

is Graham RC, Karnovsky MJ. The early stages of absorption of injected horseradish peroxidase in the proximal tubules of mouse kidney: ultrastructural cytochemistry by a new technique. J Histochem Cytochem 1966;14:291-302.

${ }^{16}$ Burkert M, Stein H, Bouman H, Lennert K. Demonstration of intracytoplasmic immunoglobulin, lysozyme and albumin and isoelectric focusing pattern of tissue immunoglobulin in socalled reticulum cell sarcoma (immunoblastic or large cell lymphoma). In: Müller-Ruchholtz W, Muller-Hermelink HK, eds. Function and structure of the immune system. Advances in 
Experimental Medicine and Biology. Vol 144. New York: Plenum Press, 1979:567-72.

${ }^{17}$ Callihan TR, Braylan RC, Farnham R, Jaffe ES, Soban EJ, Berard $\mathrm{CW}$. Correlation between immunohistochemistry and cell surface markers in diffuse large cell ("histiocytic") lymphomas. Lab Invest 1979;40:244 (abstract).

is Vernon SE, Lewin KJ. Immunoperoxidase and immunofluorescence in lymph node biopsies. A comparative study. Am J Surg Pathol 1980;4:357-63.

19 Pangalis GA, Nathwani BN, Rappaport H. Àn immunocytochemical study of non-Hodgkin's lymphomas. Cancer 1981;48:915-22.

${ }^{20}$ Stein H, Bonk A, Tolksdorf G, Lennert K, Rodt H, Gerdes J. Immunohistologic analysis of the organization of normal lymphoid tissue and non-Hodgkin's lymphomas. $J$ Histochem Cytochem 1980;28:746-60.

${ }^{21}$ Curran RC, Gregory J. Demonstration of immunoglobulin in cryostat and paraffin sections of human tonsil by immunofluorescence and immunoperoxidase techniques. $J$ Clin Pathol 1978;31:974-83.

${ }^{22}$ Landaas TØ, Godal T, Marton PF, et al. Cell-associated immunoglobulin in human non-Hodgkin's lymphomas. Acta Pathol Microbiol Scand [A] 1981;89:91-101.

${ }^{23}$ Dighiero G, Bodega E, Binet JL. Differentiation ability of the
CLL lymphocyte: An immature lymphocyte or an abnormal leukemic cell? Blood Cells 1981;7:331-9.

${ }^{24}$ Papadimitriou CS, Müller-Hermelink U, Lennert K. Histologic and immunohistochemical findings in the differential diagnosis of chronic lymphocytic leukemia of B-cell type and lymphoplasmacytic/lymphoplasmacytoid lymphoma. Virchows Arch [Pathol Anat] 1979;384:149-58.

${ }^{2 s}$ Preud'homme JL, Seligmann M. Surface-bound immunoglobulins as a cell marker in human lymphoproliferative diseases. Blood 1972;40:777-94.

${ }^{26}$ Stevenson FK, Hamblin TJ, Stevenson GT, Tutt AL. Extracellular idiotypic immunoglobulin arising from human leukemic B lymphocytes. J Exp Med 1980;152:1484-96.

${ }^{27}$ Yasuda N, Kanoh T, Shirakawa S, Uchino H. Intracellular immunoglobulin in lymphocytes from patients with chronic lymphocytic leukemia: An immunoelectron microscopic study. Leuk Res 1982;6:659-67.

${ }^{28}$ Wright DH. The identification and classification of nonHodgkin's lymphoma: A review. Diagn Histopathol 1982;5:73-111.

Requests for reprints to: Dr Zoltan Nemes, Department of Pathology. University Medical School, H-4110 Debrecen, Hungary. 